\title{
The Appraisal of the Artistry of Quatation of Qian Zhongshu's Huaiju
}

\author{
Poetry \\ Wang Yanli \\ ${ }^{1}$ Primary Educational Dept., Wuhan City Vocational College, Wuhan, Hubei, PRC Postal Code: \\ 430067 \\ a'wangyanli1967@126.com
}

Keywords : Huaiju Poetry the artistry of quatation appraise

\begin{abstract}
Based on qian zhongshu's traditional poetry "huai poly poem deposit for dibon,the research emphasizes on artistry of the quotation in the creating of old-style poems, takes the four skills in the creating of Mr. Qian' s poems for an illustration and makes a simple analysis. His attitude of waiting for the chance of appearance, changing what he' ve learned into talent, quoting every proverb measurably is actually a typical feature during his creation.

The locust poly poem deposit last book in the book is Mr Qian zhongshu in his hand, and Mr. Qian only one left in the world of poetry, is made by Mr. Qian calendar life, successively in "the book of jun poem", "the book of jun nearly poem", "huai $\mathrm{Wu}$ poem", and issue the "tsinghua weekly", "AIRS," new ", "xinmin evening news", "autumn" and other magazines in Hong Kong all psalm JingXuanBen, Mr Is created but collects gathers. Poems were recorded author poetry creation by 173 between 1934 and 1989 (in the poems of a title), content involves people recollect the past, see the scenery, for yours friends and bluntly, etc., with SiYan, wu and oblique four-line but is given priority to, such as no $\mathrm{CiFu}$ verse, etc.

Poetry creation in the process, "yun" is an ancient way of commonly used rhetoric. "Luck" is quoted allusions in his works, the ancient story or have the origin to the original words, to achieve JieGuYuJin, concise or talk about meaning of the effect. Mr. Qian is a scholar, in a talent, and be in harmony for the integration of ancient and modern, Chinese and foreign academic "kunlun", its make it full of profound remoter mind and knowledge and literature made the numerous allusions in text to spill out, and make his poems on "beginning to have the source but not yet shipped" bright characteristics, as a poem "poem", eight lines with more than 20 allusions, read only feeling rich "ShuXiangQi". Again, such as "the heart", such as the classic of shoulder pain, is also because, with a pun, interesting. Sir, though there are some poems such as "the heart", "dinin to dream again", "sad", "when midnight songs", such as the qingming festival slogan "no allusions, but rare in the poem to save.
\end{abstract}

Mr. Qian, author of locust poly poem deposit is because art, the author sums up three kinds of circumstances:

1, pure with allusions, the meaning of allusion with the author's meaning, difficult points each other. Our country the ancients to the "head" of the highest requirement is "head not sleep, if her language also" . Asked the author to have superb skills, allusions to the harmony of fiber and flesh of his work, extinguish because all the chisel marks and needle and thread, understand the allusion of the readers more lenovo and taste. Mr. Qian in creative practice is to achieve the allusions and other figures of speech and the context of the baked trust with aesthetic pursuit harmony together, "head not make people feel". Such as "lake lemone namely mesh" ", midnight not hold carry to China's own good lake mountain." Before use "zhuangzi · great master" "hide, boat, hidden mountain in jersey, is solid, but the midnight of negative and go strong, the mei know also" the Canon of after an inverted dongpo "drunk WangHu of June 27th floor of the five" "more on I had no home to live, good home without the lake mountain". Then Mr Such as 1934 fewer for the return of the native miscellaneous poems "also when the morning window arouse listen to sentence:" study on the basis of standard must from yi-qing liu song "focuses on" "in the song dynasty and jin yanzhou secretariat of pei countries, (have) a better buy chicken, taste love even, a constant cage 
between the Windows. Hence the chattering, chicken and place to talk about, very have wisdom, ceaseless all day long. In cases of so big work into." (see also "the art type" this) to tang Luo Yin the topic Yuan Xi younglab people "in the" chicken night still open window scroll, fish sill spring exhibition line." Again to han yu's "first, give walks swim south 16" arouse the window all start, rush day belongs to the west." This a few allusions to reasoning: "window dressing" window "chicken" is the cult of the author barrage tenements intellect, built as a "morning" window, under the "call" the word points clear, response window "chicken" of chicken, because and make people unconsciously.

2, "ready-made allusions analogy literally, own new idea; the fault and its serious, sit real thought forced". Goethe teach composition when once said: "composition when bees as a model of reading, read widely and proceed from melting flowers to form blindly, both history and does not have." Mr. Qian can be said to be "well-read and proceed from melting flowers form blindly" master of creation. His creation has a class description on looks "is history", but "will be wrong and seriously, its real thought forced", "innovative", it is difficult to put them one by one accordingly, because they already have new forms, new contents and new fun and allusions in it is like "water fe, glue is blue in color. Decision is to have, but and its shape". If less Mr. Qian for the return of the native miscellaneous poems "shallow dream deep curtain man did not wake up, sleep sound street called butcher Song xing." Can act "curtain", "deep" (hidden in the deep courtyard), "dream", can not sleep depth theory, and the author slants to the "shallow dream" and "the curtain", that is virtual and reality, but because the wine for the 'in', so it can be "cut off"; both the principality, thus the seductions' meat 'and are' curtain 'can' locked 'reason' dream 'dream since the "light". Again, such as the occasional book book of poetry by born 26 years ago DianXie wave flow like dust after book chapter ten "in the age of" old cream used since the new snow, cold see ice appearance "by the way, there is no origin" snow ", but because of lu you have "patio spring" : "the time change, sigh a belt around left, some new temples to frost." A canonical, said lu you have cream "new", then when can I had been thought that forced "sit" to "old" snow, abandon new Chen. Author once since the cloud: "must be both than bamboo, so as wind; ant is effective, so should fly; blood comb 'room number already, also open an account. Both ready-made allusions analogy literally, own new idea; the fault and its serious, sit real thought forced", as a solution. Him as a "Shanghai west village in WenXiao Angle" : "at first dream broken glue is difficult to continue, gradually bring sorrow to cut the mo." "The dream" like a lyre, reason to renew glue; Sorrow as creeping weed, so cut and mo can eliminate. "Tears" : "means such as ink Jian often difficult net, if for field irrigation was not deep." Than the "meaning" is the "ink", namely "hard Jian net"; Than "love" as the "field", namely "irrigation is not deep," and so on. Can this kind of allusion, is the most representative economist creation, is also the hardest place to analysis. We like to explore their origins or educational background, or it is think of as "see ZhuangFu of abdomen fruit skin of masters of judah, to the ox. Sheep, ask people one by one source of strength, what a ridiculous", if we categorically specified is origin or remote socket in which a description or allusions, or lost again far-fetched, but if we say Mr. Qian is inspired and influenced by the lift of the Canon of, ready-made allusions analogy literally, own new idea; Is gather qunfang, and then be blindly, it is not wrong at all.

3 , and abandon its meaning with the word, the meaning of the author and the original allusion basic has nothing to do. Such as "fog" "pneumatosis without cutting into the muddy day, hanging cloud sea Liu Quan sink." Said the fog, poetic flavour is very big, as when the chaos at the beginning of open, sea of clouds cover over all the land. Poem "pneumatosis" for "example, tianrui" "qi someone sorrow collapse of heaven and earth, was killed by us, could not waste; and mixed his concerns, due to xiao zhi, said, 'oh, pneumatosis ears, wu wu qi."' "muddy day" for our "peaceful" volume 2 lead sorted the day chinese-speaking yue: "speech objects are three: a week of time, two yue xuan night, three yue muddy day." "Cloud" of the zhuang zi, xiao yao you "peng's back, and I do not know its thousands of; anger and fly, if its wing hang down in a cloud of the sky." Su shi "the river, the winter that is something" : "day spring Yin hang cloud heavy. Sit in half drunk, outside the curtain will deep snow." "Bathygenic" out of "zhuang zi, the Yang" : "the party and the violations, and despise and the burden of heart, is bathygenic also." Wang chong "on short scale, 
xie", "the man who knows the ancient today bathygenic, but also so-called bathygenic Confucian scholars." This sentence, "gas", "cloud", "muddy day", the term "bathygenic", is of an ancient, not just as a cult. But in the author's poems, the words all the original features, the authors abandon only improve e-bank service quality, only literal meaning, look like the old and new, wonderful between like and don't like, for a word can make alone, not "a thief blunt" is also. Him as a "sent sorrow" mouth cannot speak book, all welcome chests up and down." "Back to Oxford nao Aaron garden (Norham Gardens) Clinton combine" old "when the door is summerwood Yin Yin, around the house fall slowly open flowers." And so on.

Mr. Qian once said "although han yu said, 'but of doing business to', and he said, 'but the ancient words from their own, drop and cannot but Piao thief, but he also said he was' peep Chen made up by stealing; although JiaoRan' steal the most obtuse thieves', 'there is no place to escape punishment,' meaning 'steal' also 'mood not the original, but he also said' steal potential to skillfully Italian fine ', 'from the hook." Wang anshi was sarcasm han yu "at the end of the overburdened kua to vulgar, poor does not cost spirit" 6. So the cloud "the wind is blunt thief". "Meet, the most obtuse thief steal language." Mr 7 but the book of poetry, nine times out of ten are made "steal" disease (i.e., the so-called "the sink when source" "endowment books that poem"), and the author knew "is a song poetry - might as well also added features - the big lesson to us, also can saying is the old contained the big lesson of the evolution of the poetry." And MAO zedong, opened a "drink the only source of" remedies, oneself cannot do, only "dinin to dream round female", "when the midnight song" and so on several can first out near, visible as incontrovertible truth is easier said than done, nor like Mr. Qian to the people outside.

Mr. Qian's poems Canon art, investigate its fundamental, is closely connected with the research experience of Mr Life. One is Mr. Qian lifetime lapping song poetry. The characteristics of song poetry YanYuCeng summed up as "in text for poetry, to learn, to talk about as poem", three only allusion logo are most likely to appear as a learning so allusions will become a poet or held the most relish content. In Chinese literary history, can see a lot of the author, enthusiastic praise highly and imitating, in verse rushed to take things personally. To heighten public awareness to the wei jin southern and northern dynasties, the head has, to the song, it is to reach the limit. "Jiangxi poetry" is not only a great show, "there is no words not to place" and "DianTieChengJin" as a creative way, is wang anshi, su shi poems such as everyone is all wrapped up in and what's more, huang tingjian said "old du poetry, the composition of back, no words not to place; cover future generations to read less, so call Han Du made comments. Ancient for articles of can edify, all things are from the ancient people of doing in calligraphy, such as magic a grain, DianTieChengJin also" pet-name ruby. Mr Thirties of the 20th century's "talk about art recorded", this paper discusses the song dynasty poet has considerable length and work, put forward many of the original beyond the obvious. The song poetry neatening $\mathrm{Mr}$ Is the theoretical basis for its poetics thought, from the perspective of artistic value and artistic innovation, fine comb and screening of song poetry. Two, Mr. Qian in the friends and teachers, respond most scholars are to learn the song, especially Mr. Qian but first teacher - Chen Yan, tapping the poetry is to Canon for "the one" of "jiangxi poetry", "zhen stone heritage room" in allusion to embody learning full of praise, as he said ji Chen salty "head cut exception", praised the dragon yu born because "natural cut, natural and graceful. Have the educational background, beneficence, smoked, coupled with Mr. Qian friends to learn, to economist in the poem, pleased with allusions, good artistic conception, renovated it not to blame. Mr. Qian had said about their learning experience of the poem: "nineteen years old start to learn crambo, good YiShan, para elegance of the beautiful body, to wit, the whole shi, huawei has carved a booklet (note the press:" the book of jun poem "). By Europe, wade ShaoLing, haowen, JuanHuai home countries, and also tend to be like you have done. Since returning from a change of old, refining refined grid, especially the careful. Every word is the source and not yet shipped, and hence to song poetry I. But to with ancient and modern poetry, the early unbiased addicted, and also made with the light body to the west is very different. If the Song Xian JiWei like, not also yue has the ear of your-self. Since the call in ShaoLing, tolo, liuzhou, dongpo, jing gong, valleys, JianZhai, haowen, zhong is the set of hard Qu. Little poetry, and pathetic, this is with thought gradually in, old brush, 
or disease my poem a "tight" word, is also known." Attending the locust together save poetry "is the old age," with fine gradually into the, the calligraphy is a bit too old ", but because of like, because, not to take off the air of a person, "drive Canon nationalities, every word has a source, a word origin, easy and 'how's sense of honor in the memory." was the true style of Mr. Qian.

\section{References}

[1] the YanShi family precepts articles"

[2], qian zhongshu, recorded about art, Beijing zhong hua press, 1984, p. 1984

[3]. Qian zhongshu, the preface to song poetry, neatening), Beijing, people's literature press, 2005 page 22

[4], qian zhongshu, tube cone plait, Beijing zhong hua press, 1986, p. 1986

[5]. Qian zhongshu, recorded about art, Beijing zhong, 1984 page 45 